\title{
Factors that influence perceived disengagement in anatomy and physiology within undergraduate nursing
}

\author{
Michael Todorovic ${ }^{1,2}$, Amy N.B. Johnston ${ }^{3,4}$, Steven Bentley ${ }^{1}$, Grant Williams-Pritchard ${ }^{2}$, Matthew J. Barton*1,2 \\ ${ }^{1}$ Menzies Health Institute Queensland, Griffith University, Gold Coast, QLD, Australia \\ ${ }^{2}$ School of Nursing and Midwifery, Griffith University, QLD, Australia \\ ${ }^{3}$ Department of Emergency Medicine, Princess Alexandra Hospital, QLD, Australia \\ ${ }^{4}$ School of Nursing, Midwifery and Social Work, The University of Queensland, QLD, Australia
}

Received: August 20, 2021

DOI: $10.5430 /$ jnep.v12n2p50
Accepted: September 21, $2021 \quad$ Online Published: September 28, 2021

URL: https://doi.org/10.5430/jnep.v12n2p50

\begin{abstract}
Effectively engaging nursing students in the study of Anatomy and Physiology (A\&P) remains an ongoing challenge for educators. The aim of this study was to investigate factors that influence nursing students' disengagement with A\&P. A pragmatic mixedmethods, quantitative dominant approach was used. Students and educators mutually agreed that paid work and amount of course material were perceived causes for student disengagement and agreed that course learning resources were not a contributing disengagement factor. Paid work commitments appeared to be a disengagement factor independent of each demographic covariate. Lack of motivation scored highest in the youngest age group (17-24 yrs.), family commitments scored highest in the non-native English speakers, and limited prior knowledge of the subject area was significantly higher for students without previous biological knowledge. Students and educators were generally in agreement regarding their perceptions of factors that negatively influence student disengagement with A\&P courses.
\end{abstract}

Key Words: Engagement, Nursing, Education, Biosciences, Anatomy, Physiology

\section{INTRODUCTION}

There is an increasing body of evidence demonstrating that Bachelor-degree educated registered nurses in acute care settings provide superior patient care, demonstrated by reduced patient morbidity and mortality. ${ }^{[1]}$ A multisite study drawing upon data from 300 hospitals from nine European countries found that for each $10 \%$ increase in the proportion of nurses with a Bachelor's degree qualification there was a 7\% decrease in mortality, ${ }^{[2]}$ and similar data from North American hospitals support these findings. ${ }^{[3]}$ Confirming that Bachelor-educated registered nurses are a means of reducing preventable hospital deaths. These pioneering studies did not speculate on what components of a nursing degree may contribute to this profound difference in patient outcomes, but it seems reasonable that a strong theoretical basis for informed clinical reasoning and clinical judgement would be one crucial component. An essential facet of the knowledge required for effective clinical reasoning includes a comprehensive grounding in the biosciences (anatomy, physiology, pathophysiology, pharmacology, and microbiology/infection control). These bioscience courses form an internationally recognised, indispensable part of every nursing curriculum, underpinning all nursing practices and assessments. ${ }^{[4,5]}$

Despite the recognised need for effective bioscience courses in pre-registration nursing programs, these courses have traditionally been problematic for educators to deliver success-

*Correspondence: Matthew J. Barton; Email: m.barton@griffith.edu.au; Address: Griffith University, 2.63, Clinical Sciences 2, level 2 (G16), Parklands Dr, Gold Coast, QLD 4222, Australia. 
fully. ${ }^{[6]}$ Challenges arise in part because of the tensions between the expansive content to be delivered to a large proportion of 'science-phobic' students, while simultaneously accommodating students' various educational backgrounds and capabilities. ${ }^{[7-9]}$ Many students have heightened levels of anxiety when initially introduced to these courses and subsequently disengage early. ${ }^{[10]}$ The contemporary tertiary student, more broadly, faces considerable responsibilities outside the classroom (i.e. employment and family commitments) that pose further challenges for bioscience educators committed to mitigate student disengagement. ${ }^{[11,12]}$ We expect that these are only some of the reasons why preregistration nursing students disengage and struggle with bioscience courses. Much of the research exploring nursing student disengagement with bioscience courses has focused exclusively on the student perspective, with few studies investigating the perspective of educators. ${ }^{[13]}$ This limited, uni-focused approach is unhelpful, because successful learning requires a commensal relationship between educators and students. ${ }^{[9]}$

In this study, we identified some factors that influenced undergraduate (pre-registration) nursing students' perceived disengagement with studying bioscience courses and explored whether these factors correlate with the perceptions of educators who teach similar courses to elucidate factors that contribute to student disengagement. Such findings can help develop a framework for ongoing mitigation of disengagement for these crucial gateway courses.

More specifically, the study aimed to:

(1) Determine whether a perceived factor of student disengagement is significantly over-represented within any one specific student demographic (cohort 1a).

(2) Identify factors that influence perceived disengagement within undergraduate nurses, using both a standard and disengaged cohort (1a and $1 \mathrm{~b}$ ).

(3) Determine the degree of alignment of factors that influence perceived student disengagement between nursing students and bioscience educators (cohorts 1a, 1b and 2).

(4) Compare the effect of external factors (non courserelated) vs. internal factors (course-related) on perceived student disengagement.

\section{MethodS}

\subsection{Research method}

We used a pragmatic mixed-method, sequential quantitative dominant approach to address our research aims. ${ }^{[14]}$ The design of this study included initial semi-structured, focusgroup interviews $(\mathrm{n}=10)$ to obtain descriptive information and facilitate theme identification that was then used to design a more extensive online quantitative survey for students, educators and a separate cohort of disengaged students.

\subsection{Focus group (theme identification)}

We undertook a semi-structured focus group interview with ten nursing students (volunteers recruited from an email sent via the University nursing student database) from one Australian University. The group interview was conducted in person, lasting approximately 45 minutes. The semi-structured format allowed predetermined open-ended questions (see Table 1) to be put to the students with the opportunity to probe further to clarify the meaning of the students' responses. ${ }^{[15]}$ The interview questions, were intended to explore students' perceived reasons for their (and their fellow peers) disengagement within anatomy and physiology (A\&P). From the interviews, we used a systematic and rigorous approach to inductive analysis of the qualitative data, following the methodology of Braun and Clarke. ${ }^{[16]}$ This analytic process started with the research team familiarized themselves with the student responses and then independently initiating a process of data coding, initially individually and then collectively via team consensus discussion. This aided the obvious clustering of data, assisting with the recognition of themes in the student responses around disengagement. These themes were reviewed and discussed by the whole team for perceived 'fit' - supporting the identification of central organizing concepts. ${ }^{[17]}$ The themes were then defined and named - forming the foci of the subsequent quantitative survey. ${ }^{[16]}$ The research team included academics from a variety of backgrounds, including genetics, neuroscience, nursing and adult education. This ensured that researchers with a variety of theoretical assumptions, disciplinary knowledge and research training, as well as personal and professional perspectives, collectively developed as affirmed the themes.

Table 1. Focus group questions used to guide student focus groups

- Please describe your overall learning experience with the A\&P courses

- What aspects at University increased your commitment/engagement in the A\&P courses?

- What aspects at University decreased your commitment/engagement in the A\&P courses?

- What things outside the University influenced (positively or negatively) your commitment/engagement in the A\&P courses?

- Are there any other factors that you believe negatively impacted your commitment/engagement in the A\&P courses?

\subsection{Quantitative online survey}

Themes identified (see Table 2) from student focus group discussions were used to develop a comprehensive online sur- 
vey using the software LimeSurvey, hosted at our University, Australia. LimeSurvey is an open-source research survey tool software that is used widely in many Higher Education Institutes. ${ }^{[18]}$

The online survey covered 12 categorical factors for student disengagement that were answered through 5-point Likert scale quantitative questions. An optional open-ended section was included for respondents to provide further qualitative information. This was critical to ensure that there was scope for themes not identified in focus groups to be represented in the findings. The 12 questions were created based on the themes identified in the focus group interviews (see Table 2) as well as additional demographic information questions (see Table 3). A group of experienced bioscience educators $(n=8 ;>10$ years bioscience teaching experience from three Australian Universities) reviewed, discussed, and refined each survey question to determine appropriate meaning; sequencing in the survey; and to ensure a suitable reading level and language (e.g., instructions, definitions, etc.). To explore the degree of alignment between students and educators, the same survey questions were provided to all three groups. All survey data were maintained on a secure server and supported by the eResearch Services at our University.

\subsection{Data collection and analysis}

The survey was distributed to participants (all whom were de-identified) from three separate groups:

Cohort 1a) second-year undergraduate nursing students enrolled in a Bachelor of Nursing (BN) degree at one Australian University.

Cohort 1b) disengaged undergraduate nursing students enrolled in a BN degree at one Australian University. This cohort was obtained through a separate process and time period than those from cohort 1a. Disengagement was ascertained through cumulative scoring metrics drawn from the University's learning management system (LMS; blackboard). Disengagement metrics included accessing the course LMS site, completion of formative and summative online quizzes, attendance at school-based orientation day, and class attendance.

Cohort 2) bioscience educators that teach undergraduate nursing students from different Australian Universities.

Table 2. Thematic analysis from focus groups

\begin{tabular}{|c|c|c|}
\hline Question & Example & Extracted foci \\
\hline $\begin{array}{l}\text { What aspect at University } \\
\text { increased your } \\
\text { commitment/engagement } \\
\text { with A\&P }\end{array}$ & $\begin{array}{l}\text { "Plenty of student help but it was hard to organise it around life and } \\
\text { placements, more about time management”. } \\
\text { "The course resources accommodated my diverse learning styles” }\end{array}$ & $\begin{array}{l}\text { Student support } \\
\text { Course resources }\end{array}$ \\
\hline $\begin{array}{l}\text { What aspect at University } \\
\text { decreased your } \\
\text { commitment/engagement } \\
\text { with A\&P }\end{array}$ & $\begin{array}{l}\text { "“I didn’t think we would cover the depth; it blew me away what we } \\
\text { needed to know” } \\
\text { 'I felt like in 2nd year it all started to click. First year was like one big } \\
\text { orientation, then once we started doing P\&P and going into the labs and } \\
\text { doing medications, procedures and things, then it started to make sense. I } \\
\text { didn't feel that at all in first year.' } \\
\text { "were not going to be doctors so why do we need to know this stuff” } \\
\text { "I had no foundation knowledge from biology or chemistry from school” }\end{array}$ & $\begin{array}{l}\text { Volume of content and } \\
\text { amount of study time } \\
\text { dedicated to A\&P } \\
\text { Relevance } \\
\text { Other course commitments } \\
\text { Limited prior knowledge }\end{array}$ \\
\hline $\begin{array}{l}\text { What things outside the } \\
\text { university influenced your } \\
\text { commitment/engagement } \\
\text { with A\&P }\end{array}$ & $\begin{array}{l}\text { "Some of us have kids and jobs and don't have the time to learn deeply". } \\
\text { "People need to be more motivated to learn, especially in 1st year', you } \\
\text { have to push through. If they can't, I don't want them looking after me". }\end{array}$ & $\begin{array}{l}\text { Family commitments } \\
\text { Paid work } \\
\text { Lack of motivation } \\
\text { Mental/health concerns } \\
\text { Social support }\end{array}$ \\
\hline
\end{tabular}

\subsection{Cohort 1a: BN students}

Second-year BN students who undertook A\&P courses previously ( $\mathrm{n}=800$ ) were sent the online survey via the University database email system. Students were not obliged or coerced to partake in the survey, as per Human Ethics Committee conditions. Participants in the survey remained anonymous. Students were invited to participate in the survey after completing their bioscience courses (minimum A\&P) to reassure them that they could not be penalised for their feedback and comments. Survey data from 284 participants were collated, 260 remained after excluding incomplete data (see Table 3).

\subsection{Cohort 1b: Disengaged BN students}

A cohort of disengaged second-year BN students who had previously completed A\&P courses were sent a link to the online survey via their University email system. A total of 103 were emailed the survey, with 19 individuals completing the entire survey.

\subsection{Cohort 2: Bioscience educators}

Bioscience educators teaching BN students at Universities in Australia were contacted via email through their respective University website. They were sent an email outlining 
the details of the survey and the purpose of the study, including ethics approval details and the link for the online survey. Educators were reassured that they were not obliged to complete the survey, and their participation would remain anonymous. In addition to the demographic questions, the educators were asked about their educational qualifications; how many years they had taught in higher education and in bioscience courses; the size of student cohort and how the courses are delivered.

Table 3. Student demographic data from completed surveys from cohort $1 \mathrm{a}$

\begin{tabular}{|c|c|c|c|}
\hline Demographics & & Count & $\%$ \\
\hline \multirow{2}{*}{ Gender } & Male & 27 & 10.4 \\
\hline & Female & 233 & 89.6 \\
\hline \multirow{4}{*}{ Age } & $17-24$ & 81 & 31.2 \\
\hline & $25-29$ & 123 & 47.3 \\
\hline & $30-40$ & 42 & 16.2 \\
\hline & $40+$ & 14 & 5.4 \\
\hline \multirow{2}{*}{$\begin{array}{l}\text { English as a First } \\
\text { Language }\end{array}$} & No & 58 & 22.3 \\
\hline & Yes & 202 & 77.7 \\
\hline Prior Biology & No & 88 & 33.8 \\
\hline Experience & Yes & 172 & 66.2 \\
\hline
\end{tabular}

\subsection{Statistical analysis}

For all three cohorts, data were collated in excel spreadsheets for analytical examination. Questions with 5-point Likert scale answers were coded strongly disagree $=1$ to strongly agree $=5$. An ordinal regression assessed the odds ratio of covariate groups to select a more agreeing response, for example, disagree to neutral or neutral to agree. The analysis was performed on each of the 12 disengagement questions using a 'main effect' model in SPSS v22. Covariate data included gender (male, female), age (17-24, 25-29, 30-40, $40+$ years), English as the first language (yes, no) and prior biology experience (yes, no). To control the increased risk of type 1 errors due to testing twelve models, one for each disengagement question, the Bonferroni multiple comparison adjustment $(\alpha / \mathrm{K})$ was implemented modifying the critical $p$-value to .00417 . SPSS v22 was utilised for graphing. ${ }^{[14]}$

The order of questions that cohorts most selected 'agreed' or 'strongly agree', from the most to least, were compared between groups using the Spearman's ranked-order correlation for non-parametric data. This analysis ranked eleven questions that were shared across the three cohorts.

\subsection{Ethical approval}

The study was approved by the University's Human Research Ethics Committee. All study investigators were certified in the study protocol and conformed to the approved human ethics guidelines.

\section{RESULTS}

\subsection{Cohort 1a: BN students}

\subsubsection{Analysis of covariates}

Analysis of age indicates that students in the 30-40 and 40+ age brackets are significantly (OR 0.350, $p=.003$ and OR $0.162, p=.001$ respectively) less likely to report 'lack of motivation' as a means of disengagement as compared to the 17-24 age group (see Table 4). Analysis of the impact of gender indicated that males were significantly less likely (OR $0.328, p=.003$ ) to rank 'limited knowledge of the subject area' as a means of disengagement than females (see Table 3 ). Non-English (as first language) speakers were significantly (OR 2.249, $p=.004$ ) more likely to rank 'Family commitments' as a means of disengagement than native English speakers. 'Limited prior knowledge of subject area' was rated significantly higher (OR 2.847, $p=.000)$ than students without previous biology.

\subsubsection{Analysis of subject}

'Other coursework and assessments' and 'Paid work commitments' were the highest scored causes of disengagement according to students (see Figure 1), and categories where students agreed (agree and strongly agree combined) to these reasons of disengagement at a higher frequency than 'neutral' and 'disagree' combined. Conversely, 'unable to see relevance of course within degree', 'assigned textbook', 'course learning resources' and 'mental/physical factors' were the lowest rated causes of disengagement according to students. Paid work commitments appeared to be disengaging independent of all covariates.

\subsection{Cohort 1b: Disengaged BN students}

A total of 103 disengaged students were emailed the survey, with 19 individuals completing the entire survey. After data curation, a total of 10 students completed the survey, which meant analysis of covariate datasets was underpowered and too stratified to determine significance. Like the previous BN students (cohort 1a), 'paid work commitments' and 'family commitments were among the highest scored causes of disengagement (see Figure 2). However, unlike the other two cohorts, 'lack of motivation' and 'personal issues' were the most common agreed on reason for disengagement among this cohort. Consistent with the general BN students (cohort 1a), disengaged students (cohort 1b) did not believe 'assigned textbook', 'course learning resources', 'mental/physical factors' and 'unable to see relevance of course within the degree' were contributing factors for disengagement. 
Table 4. Student (cohort 1a) online survey results

\begin{tabular}{|c|c|c|c|c|c|c|c|}
\hline \multirow[t]{2}{*}{ Question } & \multirow[t]{2}{*}{ Statistic } & \multicolumn{3}{|l|}{ Age $^{\dagger}$} & \multirow{2}{*}{$\begin{array}{l}\text { Gender }{ }^{\ddagger} \\
\text { Male }\end{array}$} & \multirow{2}{*}{$\begin{array}{l}\begin{array}{l}\text { English } \\
\text { Language }^{\S}\end{array} \\
\text { No }\end{array}$} & \multirow{2}{*}{$\begin{array}{l}\text { Prior } \\
\text { Biology }\end{array}$} \\
\hline & & $40+$ & $30-40$ & $25-29$ & & & \\
\hline \multirow{2}{*}{ Other coursework and assessments } & OR & 0.606 & 0.444 & 0.584 & 0.542 & 0.778 & 1.590 \\
\hline & $p$-value & .361 & .026 & .053 & .104 & .378 & .072 \\
\hline \multirow{2}{*}{ Paid work commitments } & OR & 1.646 & 0.815 & 1.190 & 0.985 & 1.039 & 1.557 \\
\hline & $p$-value & .347 & .557 & .509 & .968 & .888 & .073 \\
\hline \multirow{2}{*}{ Amount of course material } & OR & 2.392 & 0.704 & 0.936 & 1.011 & 0.549 & 1.527 \\
\hline & $p$-value & .109 & .320 & .802 & .977 & .032 & .090 \\
\hline \multirow{2}{*}{ Family commitments } & OR & 2.456 & 2.238 & 0.641 & 0.716 & 2.249 & 1.339 \\
\hline & $p$-value & .096 & .026 & .095 & .368 & $.004 *$ & .240 \\
\hline \multirow{2}{*}{ Personal issues } & OR & 2.100 & 1.305 & 1.693 & 0.503 & 0.881 & 0.642 \\
\hline & $p$-value & .161 & .446 & .047 & .063 & .646 & .072 \\
\hline \multirow{2}{*}{$\begin{array}{l}\text { Limited prior knowledge of subject } \\
\text { area }\end{array}$} & OR & 0.743 & 1.044 & 1.354 & 0.328 & 0.823 & 2.847 \\
\hline & $p$-value & .574 & .902 & .252 & $.003 *$ & .481 & $.000 *$ \\
\hline \multirow{2}{*}{ Lack of motivation } & OR & 0.162 & 0.350 & 0.658 & 0.457 & 0.519 & 0.991 \\
\hline & $p$-value & $.001 *$ & $.003^{*}$ & .117 & .036 & .019 & .972 \\
\hline \multirow{2}{*}{ Lack of social support } & OR & 0.883 & 0.825 & 1.234 & 0.855 & 0.949 & 0.804 \\
\hline & $p$-value & .816 & .588 & .435 & .675 & .851 & .384 \\
\hline \multirow{2}{*}{ Mental physical factors } & OR & 1.879 & 1.341 & 1.528 & 0.477 & 1.126 & 0.938 \\
\hline & $p$-value & .231 & .403 & .110 & .048 & .667 & .796 \\
\hline \multirow{2}{*}{ Course learning resources } & OR & 0.511 & 0.667 & 0.922 & 0.857 & 0.983 & 1.036 \\
\hline & $p$-value & .211 & .254 & .762 & .679 & .951 & .887 \\
\hline \multirow{2}{*}{ Assigned textbook } & OR & 0.894 & 1.009 & 0.856 & 0.994 & 1.432 & 1.150 \\
\hline & $p$-value & .834 & .979 & .564 & .988 & .201 & .575 \\
\hline \multirow{2}{*}{$\begin{array}{l}\text { Unable to see relevance of course } \\
\text { within degree }\end{array}$} & OR & 0.712 & 0.768 & 0.906 & 0.853 & 1.188 & 1.017 \\
\hline & $p$-value & .546 & .475 & .722 & .684 & .551 & .948 \\
\hline
\end{tabular}

Note. Reference category: 17-24-year-old ${ }^{\dagger}$; Female ${ }^{\ddagger}$; Native English speakers ${ }^{\S}$; Prior biology study ${ }^{\sharp}$. Significance reached: *, OR: odds ratio

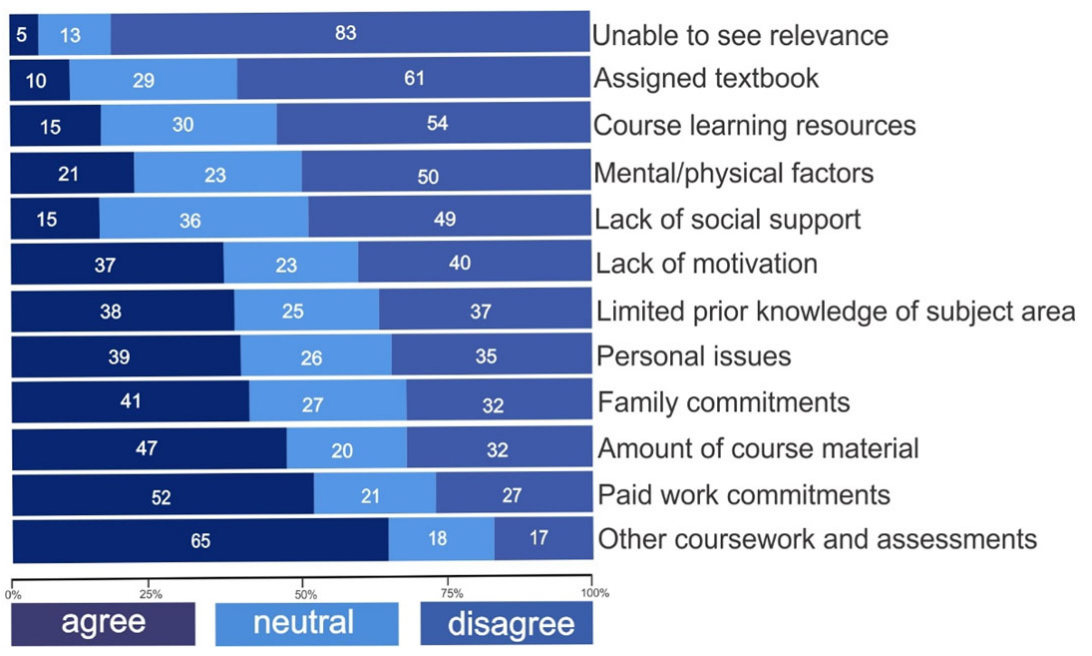

Figure 1. Percentage of student's responses (cohort 1a) based on disengaging categories $(n=260)$ 


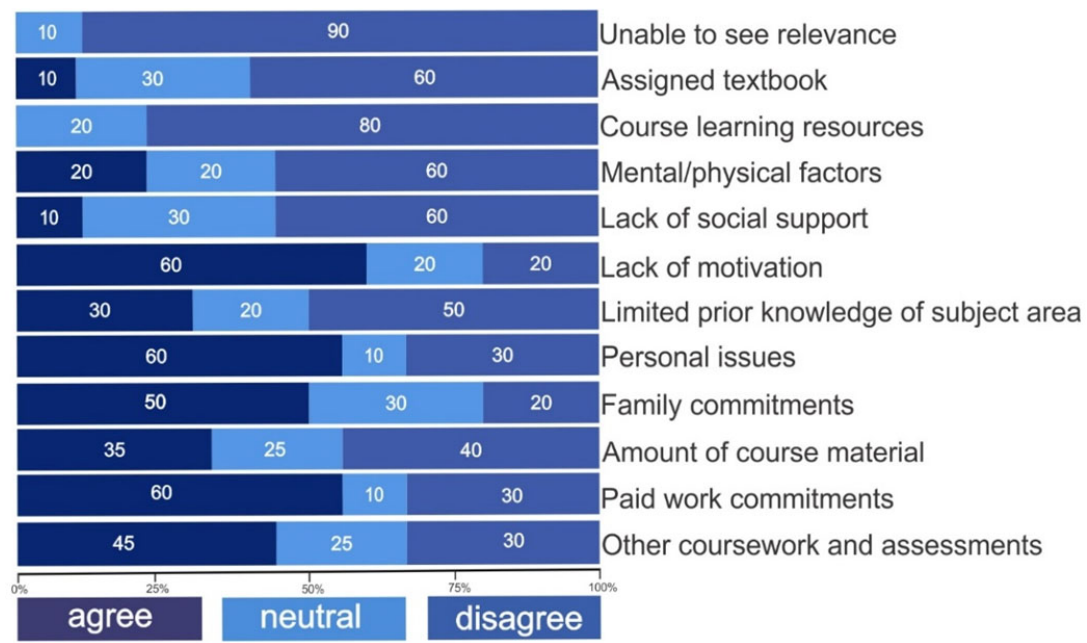

Figure 2. Percentage of disengaged students' responses based on disengaging categories $(\mathrm{n}=10)$

\subsection{Cohort 2: Bioscience educators}

A total 23 individuals completed the entire survey. After data curation, an additional 11 individuals were removed from analyses due to incomplete or idiosyncratic responses. Therefore, a total of 12 educators was subject to analysis in the study. The low number of completed surveys $(n=12)$ coupled with the large number of subgroups makes these datasets underpowered and too stratified to determine significance. Nonetheless, educators agree that 'paid work commitments', 'amount of course material', 'family commitments', 'limited prior knowledge of subject area', and 'lack of motivation' were the most likely perceived causes for disengagement in their students (see Figure 3). Educators reported that 'limited prior knowledge of subject area' was the strongest source of perceived disengagement in students, however, compared to the students' data (cohort 1a), this was only consistent in females and students without prior biology experience. Both students (cohort 1a \& 1b) and educators agree that 'course learning resources', 'unable to see relevance of course within degree' and 'assigned textbook' were not a contributing factor for disengagement.

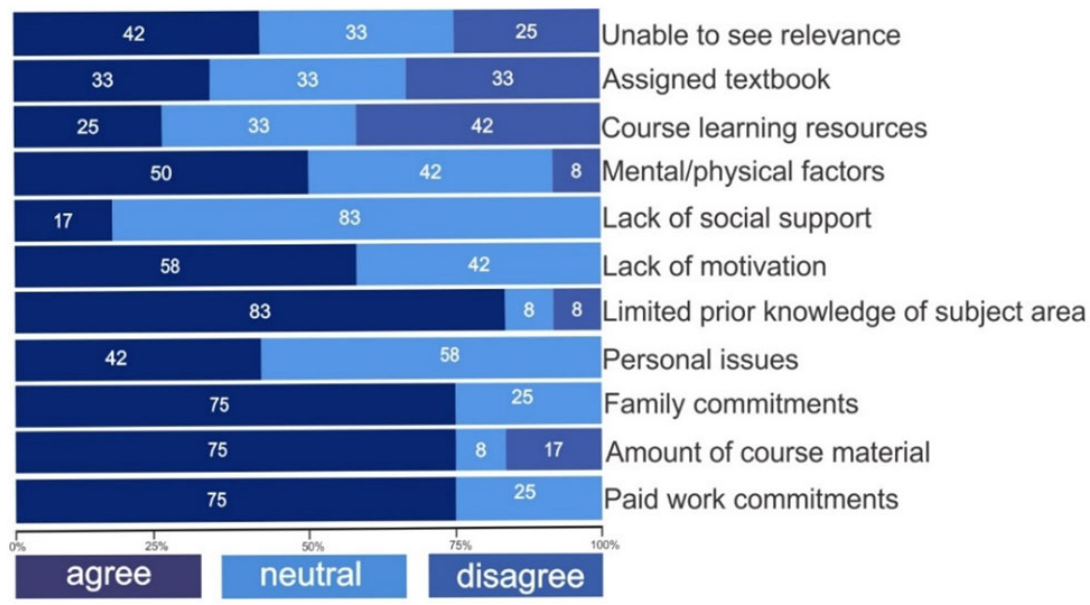

Figure 3. Percentage of educator's responses based on disengaging categories $(n=12)$

\subsection{Degree of alignment between cohorts}

Assessing the overall trends of perceived dominant disengagement factors between the three cohorts was established through the Spearman's ranked-order correlation. This analysis informs the degree of alignment between cohorts by ranking and comparing the most agreed upon disengagement factors. Here, we suggest there was significant correlation Published by Sciedu Press between all three cohorts $(p<.05)$. Specifically, BN students (cohort 1a): educators correlated $74.0 \%(p<.01)$, BN students (cohort 1a): disengaged BN students (cohort $1 \mathrm{~b}$ ) correlated $76.2 \%(p<.01)$ and disengaged BN students (cohort 1b): educators correlated $62.9 \%(p<.05)$ (see Table 5). 
Table 5. Correlations between cohorts

\begin{tabular}{|c|c|c|c|c|c|}
\hline \multirow{4}{*}{$\begin{array}{l}\text { Spearman's rho } \\
(\mathrm{N}=11)\end{array}$} & & & $\begin{array}{l}\text { BN students } \\
\text { (cohort 1a) }\end{array}$ & $\begin{array}{l}\text { Disengaged BN } \\
\text { students (cohort 1b) }\end{array}$ & $\begin{array}{l}\text { Bioscience } \\
\text { educators }\end{array}$ \\
\hline & $\begin{array}{l}\text { BN students (cohort } \\
\text { 1a) }\end{array}$ & $\begin{array}{l}\text { Correlation Coefficient } \\
\text { Sig. (2-tailed) }\end{array}$ & 1.000 & $\begin{array}{l}.762 * * \\
0.006\end{array}$ & $\begin{array}{l}.740^{* *} \\
.009\end{array}$ \\
\hline & $\begin{array}{l}\text { Disengaged BN } \\
\text { students (cohort 1b) }\end{array}$ & $\begin{array}{l}\text { Correlation Coefficient } \\
\text { Sig. (2-tailed) }\end{array}$ & $\begin{array}{l}.762 * * \\
.006\end{array}$ & 1.000 & $\begin{array}{l}.629 * \\
.0038\end{array}$ \\
\hline & Bioscience educators & $\begin{array}{l}\text { Correlation Coefficient } \\
\text { Sig. (2-tailed) }\end{array}$ & $\begin{array}{l}.740 * * \\
.009\end{array}$ & $\begin{array}{l}.629 * \\
.038\end{array}$ & 1.000 \\
\hline
\end{tabular}

*Correlation is significant at the .05 level (2-tailed); *Correlation is significant at the .01 level (2-tailed).

\section{Discussion}

This study suggests that nursing educators teaching bioscience courses, and nursing students studying bioscience courses, generally concur in their perceptions of the key factors that contribute to student disengagement. The key factors linked to perceived disengagement included 'paid work commitments' and 'other coursework and assessments'. While there was a high degree of alignment across the cohorts sampled regarding the factors that prompted or enhanced student disengagement (see Table 5), bioscience educators tended to believe that 'limited prior knowledge of subject area' was the strongest source of disengagement, unlike the students. This may have been linked to the educator's exposure to literature suggesting that previous science education (such as during secondary schooling) is a predictor of perceived ability to apply bioscience concepts to clinical (patient) scenarios, ${ }^{[10,19]}$ as well as their direct classroom experiences.

Students' perceptions of disengagement differed regarding the relative import of previous exposure to bioscience learning. Only female students and students without prior biology experience reported 'limited prior knowledge of subject area' as a reason for disengagement. However, over the whole cohort 'limited prior knowledge of subject area' was ranked sixth from the 12 categories. Confidence in the gender difference data is low due to the low number of male participants. Additionally, perhaps students without prior biology experience also reported 'limited prior knowledge of subject area' more as a self-fulfilling prophecy. Indeed, lack of prior knowledge may contribute to student anxiety, fear and apprehension in bioscience courses, which then contributes to disengagement, subsequently influencing student success. ${ }^{[4,8,20]}$ This aligns with evidence that broadly suggests that time spent studying is key to success in the bioscience courses, rather than learning style preference or other extraneous factors. ${ }^{[21]}$ This might also explain the success of interventions such as bioscience bridging courses, ${ }^{[6,22]}$ not only because these courses expose students to bioscience content early, but also mitigate anxiety around bioscience content. Which has implications worth considering for edu- cators designing student orientations and preparation prior to semester commencement. These interpretations are supported by the trend showing the more disengaged students (Cohort 1b) tended to agree that limited prior knowledge increased the risk of disengagement more than either of the other cohorts examined.

It is particularly interesting that, despite the plethora of studies focusing on learning resources provided in bioscience courses, ${ }^{[11,12,23-27]}$ students and bioscience educators mutually agreed that 'course learning resources' were not a contributing factor to student disengagement. This may be due to the increased emphasis on student retention by Universities and their focus on the provision of quality learning resources, including those that are publicly available ${ }^{[28]}$ and thus, reduced emphasis on the method of delivery. This finding certainly highlights that educators' time and attention needs to shift towards other issues rather than solely on the development of more bioscience learning resources.

'Paid work commitments' was a highly ranked perceived factor of disengagement according to all three cohorts. This reinforces nursing educational literature that demonstrates that academic performance in undergraduate nursing courses is inversely correlated with time spent in employment (paid and other), irrespective of age or gender. ${ }^{[29]}$ This is not specific to bioscience courses but extends to the whole nursing curriculum. ${ }^{[29]}$ Thus here, BN students (cohort 1a) and educators show insight. Time spent studying the biosciences can also be impacted by 'other coursework and assessments', 'personal issues' and 'family commitments'; as identified by the student participants in this cohort. Thus, these cohorts reported that they believed it was primarily external factors (non course-related) rather than internal factors (courserelated) that most commonly appeared to negatively impact disengagement.

Lack of motivation was also a key factor cited by both educators and students, and chiefly in the disengaged BN student group (cohort 1b). This is particularly challenging given the obvious import of bioscience knowledge in the development 
of clinical decision-making and clinical self-efficacy. ${ }^{[4,19,31]}$ Educator's responses echoed much of the literature in that they felt their students did not appreciate the relevance of the bioscience courses, contributing to their lack of motivation. ${ }^{[9,19,20]}$ There is, however, an apparently misalignment between student perception of lack of motivation as a contributor to disengagement (important) and relevance of the bioscience courses as a contributor to disengagement (not important). Our recent study exploring nursing students' appreciation of the biosciences for their future career, strongly corresponded with their progression through their studies; as students progress to the later years of their nursing education, their engagement with formal bioscience education decreases, while their clinical appreciation increases. ${ }^{[31]}$ The students in the current study were in second year, while the educators -who deliver A\&P - were accustomed to first year nursing students, which may explain a degree of this misalignment. Moreover, the older the student participant, the less likely they were to suggest that (lack of) motivation prompted disengagement. Akin to generic retention factors, ${ }^{[32]}$ age inversely impacted on motivation to spend time studying bioscience courses.

\section{Limitations}

The survey questions were largely based on themes that emerged from one focus group from one Australian University. This may have limited student responses and thus prevented disparate factors from emerging in findings. This is one of the typical limitations of survey data - it only responds to the questions poised. ${ }^{[14]}$ The study attempted to reduce the impact of this limitation by providing space for free text comments with the survey. The few student comments provided offered little beyond the information extracted from the 12 categories and mostly consisted of feedback on teaching staff. The small number of bioscience educators and disengaged students (cohort $1 \mathrm{~b}$ ) sampled, and restricting the study to an Australian context also limited the power of the study's findings.

\section{Conclusion}

In all cohorts there is no single demographic factor that negatively influenced perceived student disengagement from bioscience courses. However, 'paid work commitments' was independent of any demographic covariate and the highest ranked cause of disengagement according to all three cohorts. Lack of motivation scored highest in the youngest age group (17-24 yrs.), family commitments scored highest in the nonnative English speakers, and limited prior knowledge of the subject area was significantly higher for students without previous biological knowledge. Identified factors prompting disengagement were both course-related and personal (non course-related), and students and educators were generally in agreement regarding their perceptions of factors that negatively influence student disengagement with $A \& P$ courses. Engagement itself was not the focus of the present study, therefore, further research is needed to explore strategies to enhance student engagement in bioscience, and to how this would compare with clinical courses.

\section{FUNDING}

This work was supported by a School of Nursing and Midwifery, Griffith University 'Scholarship of Effective Learning and Teaching (SELT)' grant to MB, MT, GW and AJ.

\section{ACKNOWLEDGEMENTS}

We would like to thank our students whose input made this work possible and the Prof learning and teaching, Thea van de Mortel for her ongoing support of excellence in learning and teaching.

\section{CONFLicts OF INTEREST Disclosure}

The authors declare that there is no conflict of interest.

\section{REFERENCES}

[1] Liao LM, et al. The association of nurse educational preparation and patient outcomes: Systematic review and meta-analysis. Nurse Educ Today. 2016; 42: 9-16. PMid:27237346 https ://doi .org/10.1 $016 / j$.nedt. 2016.03 .029

[2] Aiken LH, et al. Nurse staffing and education and hospital mortality in nine European countries: a retrospective observational study. Lancet. 2014; 383(9931): 1824-30. https ://doi.org/10.1016/ S0140-6736(13) 62631-8

[3] Aiken LH, et al. Effects of nurse staffing and nurse education on patient deaths in hospitals with different nurse work environments. Medical Care. 2011; 49(12): 1047-53. PMid:21945978 https ://doi.org/10.1097/MLR.0b013e3182330b6e
[4] Andrew S, et al. Self-efficacy and relevance of bioscience for nursing, midwifery and healthcare students. J Clin Nurs. 2015; 24(1920): 2965-72. PMid:26238000 https://doi.org/10.1111/jocn .12933

[5] Smales K. Learning and applying biosciences to clinical practice in nursing. Nurs Stand. 2010; 24(33): 35-9. https : //doi .org/10.7 $748 / \mathrm{ns} .24 .33 .35 . \mathrm{s} 49$

[6] McVicar A, Andrew S, Kemble R. The 'bioscience problem'for nursing students: an integrative review of published evaluations of Year 1 bioscience, and proposed directions for curriculum development. Nurse Education Today. 2015; 35(3): 500-509. PMid:25534183 https://doi.org/10.1016/j.nedt.2014.11.003

[7] Craft JA, et al. Nursing students collaborating to develop multiple- 
choice exam revision questions: A student engagement study. Nurse Educ Today. 2017; 59: 6-11. PMid:28898728 https://doi.org/ $10.1016 / j$.nedt. 2017.08 .009

[8] Craft JA, et al. Registered nurses' reflections on bioscience courses during the undergraduate nursing programme: an exploratory study. J Clin Nurs. 2017; 26(11-12): 1669-1680. PMid:27571213 https : //doi.org/10.1111/jocn.13569

[9] Jensen KT, Knutstad U, Fawcett TN. The challenge of the biosciences in nurse education: A literature review. J Clin Nurs. 2018; 27(910): 1793-1802. PMid:29575462 https://doi.org/10.1111/jo cn. 14358

[10] Gordon CJ, et al. Final year Australian nursing students' experiences with bioscience: A cross-sectional survey. Nurs Health Sci. 2017; 19(1): 22-28. PMid:27704702 https://doi.org/10.1111/nhs . 12310

[11] Jensen KT, Knutstad U, Fawcett TN. The challenge of the biosciences in nurse education: A literature review. Journal of Clinical Nursing. 2018; 27(9-10): 1793-1802. PMid:29575462 https : //doi.org/10.1111/jocn. 14358

[12] Johnston AN, et al. Youtube for millennial nursing students; using internet technology to support student engagement with bioscience. Nurse Education In Practice. 2018; 31: 151-155. PMid:29906632 https://doi.org/10.1016/j.nepr.2018.06.002

[13] Friedel J, Treagust D. Learning bioscience in nursing education: perceptions of the intended and the prescribed curriculum. Learning in Health and Social Care. 2005; 4(4): 203-216. https : //doi.org/ $10.1111 / \mathrm{j} .1473-6861.2005 .00104 . \mathrm{x}$

[14] Polit D, Beck C, Hungler B. Essentials of nursing research. 9th ed. Philadelphia: Wolters Kluwer. 2016

[15] Walliman, N., Research methods: The basics. 2017: Routledge.

[16] Braun V, et al. Thematic analysis. Handbook of Research Methods in Health Social Sciences. 2019; 843-860. https ://doi .org/10 .1007/978-981-10-5251-4_103

[17] Clarke, V., V. Braun, and N. Hayfield, Thematic analysis, in Qualitative Psychology: A Practical Guide to Research Methods, J. Smith, Editor. 2015, Sage: Los Angeles.

[18] LimeSurvey G, Schmitz C. LimeSurvey: An open source survey tool. 2017, Hamburg, Germany. Available from: http://www. limesu rvey.org

[19] Rafferty B, Kyriacos U. Final year nursing students self-reported understanding of the relevance of bioscience. International Journal of Nursing and Midwifery. 2016; 8(5): 35-46. https : //doi .org/ 10.5897/I JNM2016.0208

[20] Mortimer-Jones S, Fetherston C. The nursification of a bioscience unit and its impact on student satisfaction and learning in an undergraduate nursing degree. Nurse Educ Today. 2018; 64: 1-4. PMid:29454292 https://doi.org/10.1016/j.nedt.2018.02 .006

[21] Farkas GJ, Mazurek E, Marone JR. Learning Style versus Time Spent Studying and Career Choice: Which Is Associated with
Success in a Combined Undergraduate Anatomy and Physiology Course? Anatomical Sciences Education. 2016; 9(2): 121-131. PMid:26301828 https ://doi.org/10.1002/ase.1563

[22] Owens AA. Filling in some gaps: A pre-nursing bioscience and study skills intervention. Collegian. 2019

[23] Johnston ANB, McAllister M. Back to the future with hands-on science: Students' perceptions of learning anatomy and physiology. Journal of Nursing Education. 2008; 47(9): 417-421. PMid:18792709 https://doi.org/10.3928/01484834-20080901-04

[24] Salvage-Jones J, et al. Developing and evaluating effective bioscience learning activities for nursing students. Nurse Education in Practice. 2016; 19: 63-69. PMid:27428695 https://doi.org/10.1016/j . nepr.2016.05.005

[25] Bingen HM, et al. Nursing students studying physiology within a flipped classroom, self-regulation and off-campus activities. Nurse Education in Practice. 2019; 35: 55-62. PMid:30690317 https : //doi.org/10.1016/j.nepr.2019.01.004

[26] Branney J, Priego-Hernández J. A mixed methods evaluation of team-based learning for applied pathophysiology in undergraduate nursing education. Nurse Education Today. 2018; 61: 127-133. PMid:29197687 https ://doi.org/10.1016/j.nedt.2017.11 .014

[27] Hanson J. Surveying the experiences and perceptions of undergraduate nursing students of a flipped classroom approach to increase understanding of drug science and its application to clinical practice. Nurse Education in Practice. 2016; 16(1): 79-85. PMid:26494304 https://doi.org/10.1016/j.nepr.2015.09.001

[28] Taylor V, et al. Biosciences in nurse education: is the curriculum fit for practice? Lecturers' views and recommendations from across the UK. Journal of Clinical Nursing. 2015; 24(19-20): 2797-2806. PMid:25989019 https : //doi.org/10.1111/jocn. 12880

[29] Garcia-Vargas MC, Rizo-Baeza M, Cortes-Castell E. Impact of paid work on the academic performance of nursing students. Peer J. 2016. 4: e1838. PMid:27069788 https://doi.org/10.7717/peerj . 1838

[30] Aktaş YY, Karabulut N. A Survey on Turkish nursing students' perception of clinical learning environment and its association with academic motivation and clinical decision making. Nurse Education Today. 2016; 36: 124-128. PMid:26417713 https://doi .org/10 $.1016 /$ j.nedt . 2015.08.015

[31] Barton MJ, et al. Nursing students' perceptions of clinical relevance and engagement with bioscience education: A cross-sectional study of undergraduate and postgraduate nursing students. Nurse Educ Today. 2021; 99: 104767. PMid:33571929 https ://doi .org/10.1 016/j.nedt. 2021.104767

[32] Bowles TV, Brindle KA. Identifying facilitating factors and barriers to improving student retention rates in tertiary teaching courses: a systematic review. Journal of Higher Education Research. 2017; 36(5): 903-919. https://doi.org/10.1080/07294360.2016.126492 